\title{
From turn-by-turn to larger chunks of talk: An exploratory study in psychotherapeutic micro-processes using conversation analysis
}

\author{
Michael B. Buchholz, Horst Kächele \\ International Psychoanalytic University, Berlin, Germany
}

\begin{abstract}
Independent of theoretical orientation therapies of all kind are talk-in-interaction. Influential overall conceptualizations (as e.g. intervention) belong to a certain model of medicalizing the psychotherapeutic endeavor. Talk-in-interaction is the base for applying Conversation Analysis (CA) in psychotherapeutic process research. CA is a powerful tool originating from social science taking data, hypotheses and theories from careful observing in a similar way as infant observers did. The common discovery is that conversation precedes language. Some features of infantile proto-conversation survive in adult life. CA has directed careful attention to processes like turn-taking, repair, conditional relevances, etc. in observing the rules of interaction. However, in studying psychotherapy process turn-by-turn analysis alone does not suffice. It can be completed by a new model of common ground activities and package-by-package analysis turning attention to new objects of observation in therapeutic conversation (allusions, metaphorical framing activities). We propose a methodology for both kinds of analyses based on transcribed examples from the CEMPP-Project. This exploratory designed project (Conversation analysis of empathy in Psychotherapy Process; supported by the Köhler Foundation, Germany) compared psychoanalytic, psychodynamic and cognitive-behavioral treatments in five dyads each taking transcribed sessions from the beginning, the middle phase and the end; our database includes 45 transcribed sessions.
\end{abstract}

Key words: Conversation analysis; Psychotherapy process; Analysis of metaphors; Allusion; Empathy.

Interior intellectual work is almost always a continuation of a dialogue

(Bruner, 1979, Preface)

\section{Introduction}

Our aims here are as follows. First, studying psychotherapeutic conversation is in conflict with a technical model of psychotherapy. In a rough outline we show that

Correspondence: Michael B. Buchholz, International Psychoanalytic University (IPU), Stromstr. 3, 10555 Berlin, Germany.

E-mail: buchholz.mbb@t-online.de

Citation: Buchholz, M.B., \& Kächele, H. (2017). From turn-byturn to larger chunks of talk: an exploratory study in psychotherapeutic micro-processes using conversation analysis. Research in Psychotherapy: Psychopathology, Process and Outcome, 20(3), 161-178. doi: 10.4081/ripppo.2017.257

Received for publication: 3 January 2017.

Revision received: 26 June 2017.

Accepted for publication: 30 August 2017.

This work is licensed under a Creative Commons Attribution NonCommercial 4.0 License (CC BY-NC 4.0).

CCopyright M.B. Buchholz and H. Kächele, 2017

Licensee PAGEPress, Italy

Research in Psychotherapy:

Psychopathology, Process and Outcome 2017; 20:161-178

doi:10.4081/ripppo.2017.257 this holds not only for psychodynamic therapies, but for CBT, too. Second, approaches that code and count conversation ignore the relevance of time, when something is said. Third, CA could demonstrate the high relevance of conversational details, here our aim is to step forward to a methodology of package-by-package analyses in order to see the larger composition, not only single utterances. Fourth, we pay attention to a special type of clinical thinking which includes sensitizing concepts (Blumer, 1969), advising a direction where to look; considering the therapeutic task cannot be excluded from the analysis of therapeutic conversation. We announce these aims here in advance, as we will come back to them again and again.

Recently, the term talking cure, which Freud borrowed from Breuer's patient Anna O., reappeared in Robert Woolfolk's book title (2015). This author describes how for many years in psychotherapy research the medical model of diagnosis + intervention (as formulated in manuals) + outcome measures prevailed, although serious empirical doubts questioned the medical model in psychotherapy. Wampold (2001) conducted a comprehensive meta-analysis of all available outcome studies and presented his result in the introductory chapter of his monograph:

In this book, the scientific evidence will be presented that shows that psychotherapy is incompatible with the medical model and that conceptualizing psychotherapy in this way distorts the nature of the endeavor. Cast in more urgent tones, the medicalization of psychotherapy might 
well destroy talk therapy as a beneficial treatment of psychological and social problems (Wampold, 2001, p. 2).

Later (Wampold and Imel, 2015) this position is clearly maintained. Talk therapy is conceptually opposed to the medical model, e.g. therapists have quite different roles in each model. When the question arises, how to analyze therapeutic conversation, psychotherapeutic process is not adaequately conceived in terms of patients' productions and therapists' interventions, but by conversation. Here are some methodological considerations from a CA perspective:

Conversation analysts point to a kind of unconscious dimension of interactional organization:

As it turns out, much of the interactional organization that Conversation Analysts study, while robust and perfectly amenable to formal description, exists below the level of conscious awareness of the ordinary person. (Sidnell 2013, p.79)

If this is true, self-report measures cannot sufficiently apply for reconstruction of what happens during the process.

CA, on the other hand, has proven as powerful tool in many areas (Sidnell \& Stivers, 2013) and it proves to be useful to study psychotherapeutic talk (Buchholz \& Kächele, 2013, 2016; Madill 2015; Peräkylä, Antaki, Vehviläinen, \& Leudar, 2008).

Talk-in-interaction is in the focal interest of many disciplines. Not only linguists, but also social scientists in the tradition of Harold Garfinkel, Erving Goffman and Harvey Sacks have taken profound interest in conversation. Many empirical studies were conducted and many concepts developed to analyze talk as fundamental practice that makes humans social (Levinson \& Enfield, 2006). Surprisingly however, clinical psychologists did hardly pay extensive attention to talk-in-interaction. One reason might be that interaction is different from what people think how they interact. This has methodological consequences:

As such, we cannot rely on members 'testimony as a reliable source of information about it (it being the interactional organization that Conversational Analysts study). Therefore, instead of examining what persons say they do or did in interaction, we must examine what persons actually do, and, from this, discern the analyses they have produced of the circumstances in which they find themselves. (Sidnell 2013, p.79)

Following this methodological rule CA has its fundaments in hearables and viewables - participants make every detail in conversation mutually hearable and viewable. What we deal with in therapy is more than an ex- change-of-words (Freud, 1916/17), it is embodied talk-ininteraction.

A singular constellation of various research directions from infant research, neurological science and the study of therapeutic talk evokes interests of psychotherapy process research where the social sciences cannot stand aside. Social scientific CA has the potential to bring in a special linguistic and social focus on therapeutic interaction.

\section{Relational orientation in psychoanalysis}

Although psychoanalysis had enshrined the term talking cure, the clinical interest and the theorizing efforts turned to what's going on in the patient's mind. However, since the 1980s intersubjectivity in the treatment room was rediscovered (Dimitrijevic, 2014; Greenberg \& Mitchell, 1983; Mitchell, 1988). Influential authors (Gill et al., 1968; Dahl, 1972; Meyer, 1962; Thomä, 1968) initiated the audio-recording of psychoanalytic sessions. Thomä \& Kächele published a textbook in three-volumes where clinical theory, transcribed process documentation from audio-records and research results were paralleled (Thomä \& Kächele, 1994a, 1994b; Kächele et al., 2009). One aim was to reduce the rate of drop-outs, researchers' attention to process increased. Therapeutic interaction could be described as resonating minds (Mergenthaler, 2008), a search for moments started. Clinically, moments of change (Schlesinger, 1995) were identified, the present moment became an influential conception (Stern, 2004) although it has been nowhere documented in transcribed prototypes. Others coded innovative moments (Goncalves, Ribeiro, Matos, Mendes, \& Santos, 2009; Piazza-Bonin, Neimeyer, Alves, \& Smigelsky, 2016) and insisted to make patients' voice hearable (Henretty, Levitt, \& Mathews, 2008). Critical moments (Leary, 2008) were analyzed by mentalization researchers and critical events described in psychotherapy supervision (Ladany, Friedlander, \& Nelson, 2005). Such moments are enacted in conversation, however transcriptions are rare.

\section{Relational orientation in cognitive behavioral therapy}

The relational turn was not limited to the psychoanalytic field. A few years ago, in Cognitive Behavioral Therapy (CBT) the technique of thought stopping was seriously tested in order to treat obsessive-compulsive disorders. However, the same techniques resulted in different outcomes when applied by Aron Beck or Albert Ellis; one of them being an eloquent conversationalist, the other less so. A rapid change phenomenon (Ilardi \& Craighead, 1994) was detected. Cognitive change was achieved during a few sessions of therapy before the entire intervention was applied. Obviously, it was not intervention that brought helpful outcome, but what was it then? With a programmatic headline Returning to contextual roots Neil Jacobson's CBT-research group rediscovered context (Jacobson, Martell, \& Dimidjan, 2001). 
Context included communicative environment. Some therapists felt stressed when their patients resisted to use the techniques recommended. Helplessly, therapists withdrew or intensified their endeavors. They conceptualized their patients' resistance as part of their disturbed cognition and proposed the same techniques again and again resulting in repeated cycles (Castonguay et al., 1996):

Some therapists dealt with strain in the alliance by increasing their attempts to persuade the client of the validity of the cognitive behavioral rationale, as the client showed more and more disagreement with the rationale and its related task. In other instances, the therapist treated these strains as a manifestation of the client's distorted thoughts, which needed to be challenged. Such interventions led to repeated cycles characterized by the therapist's perseverance in the application of cognitive techniques and the client's increased unresponsiveness to the treatment. (Castonguay et al., 1996, p. 502)

Half-heartedly it was concluded that context and repeated cycles cannot be conceptualized in terms of disorder and intervention. Successfully dealing with context and cycles in a more or less skillful way determined treatment outcome. The pull of hostility (Lippe, Monsen, Ronnestad, \& Eilertsein, 2008) could be shown to be independent of therapists' or patients' personality and theory. Interaction is a dimension relatively independent of both, personality and theory. Methodological consequences were hardly drawn. The most important was that efficacy of an intervention depended on talk-in-interaction. Intervention proved as a dependent variable. This opens the door for CA.

\section{Coding and counting or analysis of conversation?}

Many process researchers use approaches of categorizing interactions in order to apply group statistic designs. These approaches are based in the work of Robert F. Bales (1950) who attempted to classify interaction in groups by the Interaction Process Analysis in theoretically grounded twelve distinct acts as e.g. shows tension, supports opinion etc. The aim was to determine how frequently such actions occur. Another tradition for the study of interaction is the CA-approach which differs in certain respects from Bales'. In CA-tradition the primary object of study are the structures and practices of human social interaction per se - not interaction as a carrier of other social phenomena. (Peräkylä 2004, p. 3). These two lines of tradition are systematically compared by Peräkylä (2004) who finds CA to be qualitative, dealing with naturally occurring data (not experimental as in Bales' work), based on induction and on the organization of interaction (turn taking, etc.). What is methodologically most important is that in CA a single act is not pre-determined by theoretical categories, but the observeration that every single act is get defined by the interaction partners through the larger sequence of acts that a single action is part of (Peräkylä 2004, p. 4). And, what is relevant for psychotherapy process studies, CA can show that emotion displays are part of the interactional business, shaped by it and contributing to it (p. 14).

Thus, CA-researchers were sceptical about codingand-counting approaches as they cannot handle a highly relevant variable in interaction: time. It is not only important what is said and how, but when. Time is studied in $\mathrm{CA}$ as seuentiality in interaction. CA differentiates between form, function and sequentiality of utterances; $\mathrm{CA}$ studies the multimodality (voice, face, gesture etc.) of particpants' contribution and has a keen eye for subtle details. Richness of information in linguistic details is often ignored by coding systems directing coders' attention to the lexical-symbolic level of meaning.

The promise of CA in comparative psychotherapy research resides in this sensitivity to detail. Earlier comparative psychotherapy process research has employed a 'coding and counting' approach, by measuring the prevalence of different verbal activities. ... While such global activities can be extremely informative, what CA yields is quite different: it seeks to show the ways in which specific interactional patterns, such as shift to the immediate experience, are accomplished in different therapies, thereby explicating what might be approach specific. (Kondratyuk \& Peräkylä, 2011, p. 328)

Although some authors correctly see CA closer to a natural science (Madill 2015, $502 \mathrm{f}$.), it is one of qualitative methods having something different to offer (Hill, 2011; McLeod, 2011; Williams \& Morrow, 2009). It can be summed up in 4 points: a) they remain closer to many clinicians' lived experience, b) they allow to hear the voice of the client and the therapist, c) they offer frames of reference for the various experiences clients and therapists have, d) and they study the many facets of cooperation and its interruptions between participants in bringing to life what is called psychotherapy. CA adds a rich knowledge in rules of talk-in-interaction that can be observed as hearables and viewables not by the scientific observer, but by the participants themselves. These are the observables in CA.

As therapeutic cooperation is achieved by an enormous amount of complex conversation, pragmatic linguistics and interaction research should therefore become an essential part of process research.

\section{Sensitizing concepts help to integrate conversation analysis with therapeutic basics}

Integrating CA with psychotherapy has to overcome another methodological obstacle. Psychotherapists talk of relationships, CA talks of conversation and talk-in-inter- 
action. For many clinicians, the step from a relational approach to the analysis of conversation is difficult. And the reverse holds true, too: $C A$ concepts cannot be inserted unchanged into gaps in therapy theory. Therapists and conversation analysts must learn each other's theories and make adjustments if the product is to be mutually useful. (Stiles, 2008, p.2)

Many expressions of therapeutic language are more sensitizing than definite concepts (Blumer 1969). You can say what the properties of copper are; but how can you describe your self or the experience of knowing your self (better than before)? Here using sensitizing concepts might be an advantage.

Russell (1918) once made the distinction between knowledge by acquaintance and knowledge by description. A self, e.g., is something we know by acquaintance, an expression to determine the fluency of personal experience without objective definition, but accompanied by some observable behavior, most prominent among them the personal idiom (Bollas, 1999) and the body. Take a non-psychotherapy definition: the totality of you, your body, your sense of identity, your reputation, and so on. It encompasses both the physical self and the self that is constructed out of meaning (Baumeister 1991, p. 315). We take this definition as an example that to define the self completely is impossible, demonstrated here by the phrase and so on. Such definitions refer to implicit knowledge of readers, the dimensions of which are infinite. Nevertheless, we can use this term in the same way as we speak of love; any attempt to define love ends in trouble. Modern concepts of self (Bromberg, 2008) see it as decentered, unitary identity being an illusion; others underline that a self has many voices (Blatt, Auerbach, \& Behrends 2008; Powers and Trevarthen 2010), its polyphony is of greater relevance than a unitary fiction. A self is a sensitizing concept, it suggests directions where to look (Blumer, 1969, p. 148). It is good practice in CA to persistently base the analysis in observables in order to prevent over-hasty jumps into wild psychological speculation (Potter and Edwards, 2013). But a self, central concept in many therapy theories, cannot be observed.

Often a self is equaled with subjective position, although on the other hand the self is described by various authors as polyphonic; the self has a multiplicity of voices (Leiman, 2012; Stiles, 1995) or a subject has infinite uniqueness (Salvatore, Gennaro, \& Valsiner, 2012). A self is created and transformed in relationships. As a Self is not an Observable, we want to introduce into CA the concept of a Concludable.

A Self can only be concluded with all the risks of error. People can be observed in how they use it as mundane term, but they can hardly be persuaded to do without. Its disadvantage of non-defineability (in a scientific framework) is an advantage in conversational practice: it provides sufficient flexibility for a coparticipant to stay in reception and participation. And it provides sufficient sta- bility: I can rely on your promise to meet me tomorrow when I can count on you as a stable self, tomorrow sufficiently-the-same as today [thanks to Georgia Lepper who turned my attention to Sacks fourteenth lecture, headline The inference-making machine (Sacks and Jefferson 1992/1995, p. 113 f.)]. CA-Authors (Hutchins \& Nomura, 2011) assume that people seek to increase coherence of experience. We assume that coherence of experience is equivalent to self.

\section{Methods}

\section{Observables and concludables}

The distinction between observables and concludables can be made useful when some rules of concluding concludables can be outlined. When speaker A determines what speaker $\mathrm{B}$ is doing $\mathrm{s} /$ he concludes from bringing together various observable practices of composition and positioning. Concludables are based in mutually observable practices. Inevitably, in concludables is an inevitable degree of indeterminacy. This indeterminacy becomes a resource for conversation continuation by creating an epistemic imbalance (Heritage, 2012) between the participants. This imbalance drives conversation.

After transformation of infant proto-conversation into conversational practice the use of language becomes part of an observable social world, although symbolic form does not correspond to material things. Symbolic meaning is instantiated by two variables: a) embodied affective expression and b) interpersonal meaning locally coproduced by participants in a given situation. From this point of view, it makes sense to talk of mind as an irreducible interpersonal phenomenon involving self, language, feeling and relationship - it is a concludable. Symbolic meaning and mind cannot be defined precisely and this, again, is an advantage in (professional and everyday) conversation.

CA can observe how meanings are defined (by participants) in a local and situational practice of conversation. In psychotherapy process, conversation gives form to significant meanings that are sometimes created together and sometimes held alone. Personal meaning cannot be quantified. Therapists and patients, therefore, use analogy and metaphor to give personal meanings articulation. They strive for analogical fit (Korner, 2015). Therapeutic responses of analogical fit support this striving for coherence. For moments, then, therapist and patient merge into what infant researcher Ed Tronick (2007) has termed a dyadic state of consciousness:

The dyadic consciousness hypothesis states that each individual, in this case the infant and mother or the patient and the therapist, is a selforganizing system that creates his or her own states of consciousness (states of brain organization), which can be expanded into more coherent 
and complex states in collaboration with another self-organizing system. (Tronick, 2007, p. 404)

Thus, a minimalistic psychotherapy framework can be conceptualized (inspired by Korner, 2015). The main task in psychotherapeutic cooperation will be both: maintaining self-coherence and enriching complexity of the self in relation to others and the material world.

But, how is this task realized by psychotherapeutic conversation? Is there something specific in therapeutic conversation? How is it implemented? In order to study this task, CA distinguishes two observable levels of analysis, the rich described interaction engine and the less well described package-by-package-level.

The interaction engine (Levinson, 2006) operates as proto-conversation from very early moments in human life. Mother and baby create a joyful experience for both for which Harvey Sacks, founder of CA, found the elegant formulation: doing together to do together [the fact that there is a job that any person could clearly do by themselves (sic), provides a resource for members for permitting them to show each other that whatever it is they're doing together, they're just doing together to do together. (Sacks and Jefferson 1992/1995, p. 147)]. It describes the observation of doing something together and the immediate selfobservation to do together. While people do together they observe their doing together. This is the earliest CA-version of interpersonal origin of mind-in-interaction. It includes a) joy as important affective experience; b) the gradual establishment of rules - who takes initiative? Who follows?

The desastrous effects of arbitrary interruption for both, mother and baby, could be shown in famous stillface-experiments (Ham and Tronick, 2009); if the mother - following the experimenter's instruction - interrupts her resonant play with her baby for two minutes only, even 4month old babies take a lot to regain mother's attention and to vitalize her frozen face. Thus, rules can be observed and new rules are established gradually, too. Human babies pass through what has been termed the nine-monthrevolution (Tomasello, 2001, 2003; Tomasello, Carpenter, \& Liszkowski, 2007). When mother points to something the baby's gaze is no more fixed to the finger but to the distant object pointed to. The baby begins to realize that mother is a subject with observable behavior and unobservable intentions that can be concluded from behavior. The distinction between observables and concludables is established during the course of development. From this experience onwards babies point to something, but their gaze controls mother's gaze; does she realize to be expected to look to the distant object? Not to the baby's pointing finger! After the nine-month revolution babies aim to gain control over (m)other's states-of-mind - realizing to have a mind as primary cause of initiative itself.

Others (e.g. Beebe, 2014) could microanalytically observe patterns of disturbed interaction, like the chase and dodge-pattern that predicts from the age of 4-months the attachment state at one year. It is not only the baby's development that is of interest here. Baby and mother cocreate a growing intersubjective field for their common development, beginning from a state of not-knowing (Trevarthen, 2011) to an individualized self. Intersubjectivity is prior to self as conversation is to language. The course of development goes from joint attention, from individual to shared to collective intentionality (Tomasello \& Rakoczy, 2009). Therein the red thread of emerging conversational abilities is embedded, as infant researchers see it. These abilities rest on the interaction engine as Levinson (2006) has termed the turn-taking organization. In later years rules like one speaker only (Sacks, Schegloff, \& Jefferson, 1974) are established - and observed [there are universals for these rules in many languages and cultures, although variations must not be ignored (Stivers et al., 2009)]. Thus, interaction engine is the first focus for an analysis of conversation.

However, psychotherapy process research by CA needs more. We use additionally package-by-package analysis and expect, that this level will bring us closer to the challenge of an analysis of concludables. CA can methodologically include what infant researchers describe as the baby's turn from the observable to the unobservable, however real. We take the idea of packages from Jefferson (2015, p.29) and Auer (2014) and add a theory of (concludable) expectations by musicologist Huron (2006). By these concepts, described later, we try to do justice to the fact that psychotherapists and patients often refer to events that were either mentioned or happened in sessions before, often weeks ago. To our knowledge, there is no elaborated methodology for analyzing this type of referential practice. We will show examples and some analytic procedure. We start with the first level (turn-by-turn) outlined so far as interaction engine.

\section{Results}

The conversation analysis of empathy in psychotherapy process-project: source of our data

For our exploratory approach, we could use data from the Munich Psychotherapy Study (Huber et al., 2011; we acknowledge the generous offer of our colleague Prof. Dr. D. Huber.) for the CEMPP-Project (Conversation Analysis of Empathy in Psychotherapy Process; Grant by the Köhler-Stiftung, Germany). We received audio-records of five psychoanalytic, five psychodynamic (once-a-week) and five CBT treatments. We made full-session CA-transcriptions from a session at the beginning, from the middle of treatment and from the end-phase. Thus, each individual treatment was documented by three transcribed sessions, enabling us to follow a course of 15 treatments. Each therapeutic orientation had 15 transcribed sessions, totalling to an amount 45 transcribed sessions. The main research question was if there is a common description - 
valid for all three therapeutic orientations - of empathy as conversational practice possible? The answer was no, there is too much difference in concepts and in relational practice. Nevertheless, we could contribute to a CA-approach to empathy (Buchholz et al., 2017; Buchholz 2016). In qualitative research it is not seldom that the data gain dominance over hypotheses; the material leads to interesting questions one had not expected in advance. And, as usual in explorative approaches, being guided by material sometimes results in unexpected discoveries forcing to new theorizing. Reading transcripts requires some practice, just like reading statistical tables or diagrams.

Here is a key to the symbols used:

words in square brackets=words spoken at the same time; colons=pronunciation of a letter is stretched out;

commas $=$ slightly rising intonation;

question mark=markedly rising intonation;

semi-colon=slightly falling intonation;

full stop=falling intonation;

underlined words or letters $=$ spoken with emphasis;

words in upper case with !=words spoken loudly;

angle brackets $=$ drawn-out slower speech;

inverse angle brackets=fast speech;

${ }^{\circ}=$ quiet words or sentences;

numbers in brackets $=$ pauses in seconds; $()=$. under 0.25 seconds; $(-)=0.25-50$ seconds; $(-)=0.50-75$ seconds; $(-)=0.75-0.99$ second pause.

\section{Turn-by-turn: a process model of common-ground activities}

A new discovered question was: Is a dyadic state of consciousness built-up between two adult speakers in psychotherapy and how can it be observed? We have analyzed our material in various dimensions and found the following steps (thanks to many helpful comments in many data-sessions to Marie-Luise Alder, Jörg R. Bergmann, Michael Dittmann, Florian Dreyer; they inspired our thinking deeply and often brought us back to track. All conclusions drawn from the material are consented in this team of productive co-workers). Following CA-tradition we observed beginning of sessions and compared them. All transcripts are translated from German.

\section{Primary Document 19, psychodynamic therapy, first session, female patient, female therapist}

$\mathrm{T}$ : I'm testing the recording again. And rewinding now, $>$ today is the $29^{\text {th }}$ of September two-thousand and nine $<$

((Recording turned off and turned on again))

$$
\text { (2.9) }
$$

((rustling sounds))

P: [ ${ }^{\circ}$ Well I can see you've (.) already set up the microphone $^{\circ}$

[loud rustling]

T: YES! $>\mathrm{H}$ ! H!< ((loud rustling))

P: ${ }^{\circ} I^{\prime} d$ already forgotten about that ${ }^{\circ}=$

$\mathrm{T}$ : =Yeah

(4.8) ((rustling paper))

$\mathrm{T}$ : $\uparrow$ Yeah ((rustling stops))

This is our analysis: The therapist talks data into the microphone of her tape-recorder, then the record is turned off. We do not know how long the interruption lasted. When the record is started we hear the patient entering and after $2.9 \mathrm{sec}$ the patient starts with silent voice uttering a little teaser (Well) and adds a verbal deictic gesture by pointing to a perceptual object (Well, I can see...the microphone). A triadic constellation begins: The patient's verbal gesture of pointing to an object in the common visual environment (to the microphone) is responded by the therapist's loudly spoken YES!. A conversational-cognitive triangle of common perception evolves composed of three components: the pointing utterance - the object pointed to - the therapist's gaze. In infant research this triangle is well known (Liszkowski, 2006; Tomasello, 2007): in just that moment when the baby sees mother turning her gaze to the object the baby knows that mother understood and the mother knows what the baby wanted - a cycle of mutuality is set in motion which makes sharing perception and knowing possible. This mutuality needs confirmation that mother and baby realize by turning their gaze to each other and uttering signs of joy because of the emotional sharing. By mutually confirming the dyadic state of consciousness, the perceptual object (microphone) is transformed into a common conversational object. Adults mutually confirm their dyadic state by uttering small tokens (oh yes, ok, I see or just $h m$ ), which can be uttered in several turns. Here, the therapist utters a pronounced and loudly spoken YES!, spoken with a sharp accent and extended, followed by a strong outbreath. It has a strong impact. The patient withdraws and slightly remarks to have forgotten this - reference is the record of the session. As the patient in her first remark uttered that she knew about the record of the session (she had given her informed consent before) this is a clear withdrawal including that she pretends to have forgotten. This withdrawing from the therapist's strong utterance is quickly confirmed by the therapist's Yeah. The transformation of the perceptual into a conversational object did not fail, but the dyadic state is not stabilized. From the pause of $5 \mathrm{sec}$ following and the restart of the interaction engine we theorized that further steps - more than transforming a perceptual into a conversational object for a short moment can be expected to follow. We looked at beginnings of another session below.

\section{Short-term psychodynamic therapy, male patient, male therapist, $3^{\text {rd }}$ session}

P: ${ }^{\circ}$ now $^{\circ}(-)$ last session you handed over to me that form here

(3.9) 
P: with the date of today, $(-)$

$\mathrm{T}:{ }^{\circ}$ yes? ${ }^{\circ}$

P: (?)

T: ${ }^{\circ}$ yea:h:,

(4.2)

P: ${ }^{\circ}$ let's hope it will be approved, ${ }^{\circ}$ (1.2)

P: ${ }^{\circ}$ well $\mathrm{ok}^{\circ}$ and I was to think about, (-) tza (-) e::r the question, ${ }^{\circ}$ why I can't be alone or why this is so difficult ${ }^{\circ}{ }^{\circ}$ for me $e^{\circ \circ}$

The patient returns a health insurance form that he had to read and sign and hands it over to the therapist. The verbal pointing gesture, again opened with an attentionattracting teaser $\left({ }^{\circ}\right.$ now $\left.^{\circ}\right)$ to the common perceptual object (that form here) operates as starter of the interaction engine in the same way as in the session analyzed before. What follows is a confirmation by slightly spoken tokens. After a break of nearly $5 \mathrm{sec}$ the patient's utterance includes a we-perspective (let's hope...), an affiliative component is in this turn (Muntigl \& Bänninger-Huber, 2016). After common transformation of the perceptual into a conversational object the therapeutic dyad links other conversational objects; here it is hope - presented as a common one - that things might go well. After these three steps - perceptual, conversational, linking - he turns to a project (and I was to think about...) the therapist and he had agreed upon in the sessions before.

When we studied beginnings of other sessions from the beginning of therapy we found that the full process goes one step further. Here is the beginning of the 7 th session of this same therapy.

\section{$7^{\text {th }}$ session in a psychodynamic psychotherapy (Primary Document 7)}

\section{((Rustling of fabrics))}

P: so, it's not you beginning; ((snorting with laughter))

P: .h

T: ${ }^{\circ} \mathrm{hm} .{ }^{\circ}$

$(2,8)$

P: ${ }^{\circ} \mathrm{mhm},{ }^{\circ}$

$\mathrm{T}$ : is this important for you, or; $(1,2)^{\circ}$ if I would [begin ${ }^{\circ}$,

P: [.h no:] no:, (-) Today, well, I just had a second thought today I won't say anything ((grin in his voice) $)$ at the beginning ((laughs)) and look what happens, $. \mathrm{h}=$

$\mathrm{T}$ : $=\mathrm{mhm}$;<smiles>[Mg][Mg]</smiles>

P: ((clearing his throat)) $(3,1)$

T: so it's more [kind of a TEST
P: $\left[\right.$ yeah;,$(-){ }^{\circ}$ really $\left.^{\circ}\right]=$

$\mathrm{T}:=\mathrm{a}$ : little bit $(1,8)$ little bit of a wrestling match $(2,0)$

P: ${ }^{\circ} \mathrm{hm}$, yeah;

We analyzed this prototype of a session start extensively (Buchholz, 2016). There is a 4-step procedure in co-producing common ground, as linguists would term it or dyadic state of consciousness, as Tronick termed it:

First, the patient points to a perceptual object of which he can be sure the therapist shares this perception: the non-start of the session can be perceived by both creating a state of joint attention. They mutually observe each other as observers having a common object. They mutually confirm being in a state of joint attention, which again transforms the perceptual into a conversational object by utterances of mutual recognition (exchange of information-receipt tokens). After such a transformation, a third step can follow, only a conversational object can be linked to other symbolic content - the therapist links with a dimension of relevance (is this important for you). The patient responds with a second thought-link and formulates a position for himself (look what happens). Then, the therapist makes a fourth step using the test-metaphor which includes a role for the therapist, too. As he is the one to be observed in the framework of the test-metaphor he can add a second metaphor of a wrestling match. The interpersonal scenario is thus outlined as a playful fight. As the wrestling-match metaphor exactly describes what is happening the two of them achieve a state where they act and at the same time talk-about-doing while they talkinto-being (Gafaranga \& Britten, 2005) what is going on between them. Tronick's dyadic state of consciousness is processed to higher levels of coherence and complexity by the skillful implementation of two metaphors.

The perceptual object with which this process begins is not an object of the material world as if the patient were pointing to a microphone. He treats his own not beginning as if it were a perceptual object, the therapist can see and hear that the patient is beginning by not beginning. This perception can be shared immediately. When both mutually confirm this step into a common conversation the common ground is prepared for further conversational steps [see the comparison of psychological and linguistic use of common ground (Buchholz, 2016)]. We call them linking activities. In this example, it is relevance. What follows quickly are two coherent metaphors making this type of starting a session an observable. However, the observable interactive logic of this process does not come to an end here.

Going through the 4 levels of perceptual, conversational, linking and metaphorical activities we can now see that the metaphorical object of the wrestling match is used as if it were a perceptual object again. The whole process starts in a recursive fashion (Corballis, 2011). Table 1 shows which conversational operations and cognitive re- 
sources are required. It's only a small number of components and a sequential order that produces a common ground and it's transformation; the step from senses (perception) to conversation and it is mutual confirmation creates a common ground as base for further operations requiring only a few cognitive resources, the recursive use of which produces the development of higher stages of conversational cooperation and insight.

This is a turn-by-turn process model for how common ground activities are organized by both participants. It includes the affective quality: patient and therapist enjoy their sharing experience, they participate in what Harvey Sacks termed doing together to do together (Sacks \& Jefferson, 1992/1995, p. 147). Both share a dyadic state of consciousness in Tronick's (2007) terms. Sharing makes moments of empathy possible, sometimes it comes very surprisingly. In different therapeutic schools different distributions can be observed.

Table 2 shows differences between the therapeutic schools in realizing conversational common ground ac- tivities in different levels. It shows a time-factor during the course of therapy; common ground activities decrease during the course of time. Both participants can be assumed, then, to know each other's relatedness mutually. Patients' productivity in generating relational metaphors is small in CBT. The analysis conducted so far focused the turn-by-turn organization of therapeutic process. The result was a process-model of four steps - perceptual object, conversational object, link, metaphor + recursion. This is the full scheme, although it is not always achieved.

The logic of this process requires certain cognitive resources - joint attention, memory, analogical reasoning, creativity [analogical fit has been described as a typical mode of psychotherapeutic thinking (Korner, 2015)]. Participants mutually observe the state of relationships from the other's responses and then withdraw or go a step further. CA uses a second-order observation (observing participants' observations) including the participants' concludables. Thus, CA can observe the steps of how a dyadic state of consciousness is composed by both.

Table 1. Levels of common-ground activities (read upwards).

\begin{tabular}{lcc}
\hline Common-ground level & Object & Conversational operation \\
\hline Metaphor & $\begin{array}{c}\text { Co-creating: } \\
\text { new metaphorical object }\end{array}$ & $\begin{array}{c}\text { New metaphor for relational activity } \\
\text { Linking }\end{array}$ \\
\hline Linked objects & $\begin{array}{c}\text { Link with other objects or dimensions } \\
(\text { e.g. relevance })\end{array}$ \\
\hline Perceptual & Objects of conversation & References to conversational objects \\
\hline
\end{tabular}

Table 2. Distribution of common-ground activities in psychoanalysis, once-a-week psychodynamic therapy and cognitive behavioral therapy.

\begin{tabular}{|c|c|c|c|c|}
\hline & All PAs & Once-a-week psychodynamic & All CBT & Total \\
\hline CG 1 perceptual & 82 & 20 & 51 & 153 \\
\hline CG 2 conversational & 74 & 26 & 47 & 147 \\
\hline CG 3 link & 60 & 21 & 33 & 114 \\
\hline CG 4 P metaphor & 27 & 19 & 9 & 55 \\
\hline CG 4 T metaphor & 21 & 9 & 15 & 45 \\
\hline \multirow[t]{2}{*}{ Total } & 264 & 95 & 155 & 514 \\
\hline & All sessions, at the beginning & All sessions, middle phase & All sessions, final phase & Total \\
\hline CG 1 perceptual & 85 & 44 & 24 & 153 \\
\hline CG 2 conversational & 89 & 37 & 21 & 147 \\
\hline CG 3 link & 48 & 43 & 23 & 114 \\
\hline CG 4 P metaphor & 18 & 22 & 15 & 55 \\
\hline CG 4 T metaphor & 20 & 12 & 13 & 45 \\
\hline Total & 260 & 158 & 96 & 514 \\
\hline
\end{tabular}

PAs, psychoanalyses; CBT, Cognitive Behavioral Therapy. 
Another new observation is that the same resources can be recursively applied when the metaphor is treated in an as if-mode: taking the metaphor as if it were a commonly created perceptual object can make the process start recursively. No new resources are required, but higher levels of interaction can be achieved. The turn-byturn analysis shows how higher levels of complexity are achieved and climbs the step to more symbolic or metaphorical description of events. The patient's coherence-of-self is kept and at the same time the complexityof-self-understanding is expanded. CA and psychotherapeutic concepts enrich each other.

\section{Package-by-package-analysis}

Such mutual enrichment is met on more complex levels when we start to analyze packages of conversations. Jefferson (2015, p. 29 f.) writes, how her analysis of conversation which I practice tends to focus on very small, crystalline bits of the conversational machinery. She wants to overcome this limitation and quotes Harvey Sacks who mentioned the possibility, that this kind of crystalline analysis, characterizing some two or three utterance sequence which occurs in some larger fragment, completely ignores how the sequence fits into that fragment, or how it is part of the analytic package that is being developed. Package-by-package analysis tries to approach the question of how single utterances are part of a composition.

What patients tell in therapy is often widely dimensioned, exposing full narration of a personal life or world view or detailed description of single events and it takes long time where therapists often cannot do more but uttering tokens from information received to change-ofstate (Heritage, 1984). Jefferson's and Sacks' considerations can be methodologically detailed in three consequences:

a) Therapists work on small crystalline details which are embedded in a frame of references constructed by big narrative elements following a project to give details another, a new and unexpected nuance or meaning, aiming to shift patients' disavowed into more acknowledged agency.

b) Therapists learn to consider their own bodily reactions as a kind of adjacent or quasi adjacent structural resonance in which prior talk becomes part of a new, unfolding syntactic project and enters into that particular relationship between prior and emergent talk that is often called ellipsis (or better, analepsis) (Auer 2014, p. 14).

c) Therapists in later (parts of) sessions come back to these big packages (Jefferson) and use them for many purposes. This requires a memorial capacity for details of stories, until now not well studied nor understood.

Thus, we want to go on to package-by-package analyses following this methodological list.

\section{Shifting agency}

In a first session of a psychoanalytic treatment a female patient tells how she suffers from the separation of her boy-friend who abandoned her, how he rebuffed her and years of common life and how he now enjoys his new life and then she adds:

\section{Primary Document 7; Psychoanalytic therapy, first session}

P: I cannot accept it the way it is (-)

$\mathrm{T}:{ }^{\circ} \mathrm{mh}=\mathrm{h}^{\circ}$

P: and focus myself onto my life (-) I cannot manage this ta:sk

P: ((sniffs) $)(-)>$ and again and again I fetch the old pictures $<$ from our holidays=and (1.4) a- from our flat and ((sniffs)) him as man (-) errm (1.5) I see: $(-)$ nothing bad any more in our relationship=wha:t ((swallows)) wonderful times we had together (.) nothing BAD (-) ((sniffs))

(13.5) ((she deeply breaths in and out))

$\mathrm{T}$ : .hh yea:h then of course it is really difficult to understand (-) that now you shall be no longer together with him (-) ain't you?=

$\mathrm{P}:$ = exactly.=

$\mathrm{T}$ : =that a door fell closed when he (-) shut of you and let you stand (-) outside in front of it;

P: yes (.) exactly=

$\mathrm{T}$ : $=\mathrm{h}{ }^{\circ}$ that you have to suffer from that loss that way so hard; ${ }^{\circ}$

P: yeah-

P: .hh (-) hh (-) yes (-) precisely so it was .h $(($ sniffs $))$ and exactly these images play again and again in front of my inner eye how this (-) how at that time he was gone and really slammed the door behind himself

Looking back into the history of her relationship the patient describes how she actively changes her images of memory, how she alters bad into good experience by selective viewing and remembering. She describes how it appears impossible for her to focus myself onto my life. The female therapist shows how just this autosuggestive strategy makes it difficult for her to conceive of her situation how it is, that she can no longer be together with her former boy-friend and she uses the metaphor of the closed door as illustration for closing an era in her personal life. Surprisingly, the patient responds that this is not a metaphor but an event that really happened. Metaphorically expressed empathy uses the pictoriality of culturally transmitted experiences; closing a door behind when leaving is a frequently made experience. However, this metaphor advances to a new step, the patient makes an 
experience of being deeply understood by a therapist who seems to know what really happened - before the realistic story was told. The therapist managed to establish a dyadic state of consciousness and this helps the patient to acknowledge how her boy-friend really slammed the door. For a moment, the patient accepts this reality and regains her agency.

This package has a format consisting of a) complaint and self-diagnosis [Jefferson $(2015$, p. 32) describes a format of trouble talk. Step D in this format is callled Work$u p$ and includes the observation that in trouble-talk diagnosis and self-diagnosis (in an everyday fashion) can be systematically found. Later she writes: I simply note a patterned occurence in troubles talk of a range of activities, including diagnoses, reports of relevant (similar or contrastive) experiences, relationalized remedies and prognoses. (p. 44). From this conversational point of view the medical discourse in psychotherapy research, of which we talked in the introduction might be considered an every-day-practice disguised as medical]; b) focusing the patient's agency in the complaint; c) introducing the course of time by the door-metaphor; d) reframing the suffering as self-induced by her autosuggestive strategy; e) with an unexpected effect that the door-metaphor becomes validated by the patient as a real experience; $f$ ) which helps to regain the patient's agency. Agency shifts from passive suffering to actively rediscovering an element of experienced reality, followed by surprise. Both therapist and patient treat and meet each other as people thinking about thinking people. This includes an element of common cultural experience.

\section{The allusive shock}

There are packages that are much more complicated which can be illustrated by an interesting observation about dream-telling (published in detail by Alder, 2016). In a 4th session another female patient talks about her interest in dreams; that she had series of repeated dreams, that she likes dreaming and sees dreaming as part of herself. Her female therapist upgrades the relevance of dreaming by asking a lot about this and that and in this way both discuss dreaming for about 12 minutes - until the therapist, out of the blue, declares that she does not understand dreams, but that she however has a clear opinion about them. Then, in a surprising turn of self-disclosure the therapist tells a dream of her own in order to demonstrate that dreams are as fleeting as fog. Now the patient starts telling another dream she had the night before where she was left alone naked in a forest and with burned hands. Somebody came along, asking some questions and then said good-bye and left her alone in her state of emergency.

This dream is ignored by her therapist, again. Conclusively, she follows her conviction not to understand anything about dreams. However, we can learn from the transcript that dreams sometimes operate as a comment on or interpretation of an ongoing interaction. The telling of this dream was an allusive interpretation of what was actually going on during the interaction from the patient's point of view. It was an allusion because the patient did not complain in direct words that she basically burnt her fingers in talking about her dreams and that the therapist left her alone. The telling of the dream used allusion as a means of hidden conversation. In order to see the dreamallusion it proved methodologically necessary to take the package of the whole session into view.

What are allusions, then?

Allusions have a format of several components: a) they say something and don't at the same time; b) they avoid direct assessments by recipients, c) they leave the conclusive interpretation of what was said to the listener and d) at the same time do not disturb the affiliative bond, e) they appear to be spoken without distinct motivation, f) the speaker is exonerated from responsibility, as nothing was said, f) the recipient has a double burden: responses are blocked since it is difficult first of all to decide what was said and heard.

From this observation CA can conclude a methodological rule: In order to detect allusions one can look to longer pauses - what was said before? Inspired by this impressive example, we found that allusion was not given much attention by CA (except Schegloff, 1996).

Here is an example where a female patient in her 15th therapy session uses narrative illustration and direct citation of a male colleague's behavior that she explicitly categorizes as allusion. She feels bothered:

P: he comes into the room then $(-)$ [he just interrupts

T: $[\mathrm{mhm}$

P: us (.) stands with us and joins in the conversation even though he wasn't invited

$(-)$

P: he makes sexual allusions, so when you $>>$ ask for example $<<$ is there something I can do for you (1.4) the:n $>$ he says $<$ (.) $\uparrow$ yeah of course there is $>$ something you can do for me $<$ (-) A:nd but [he] doesn't notice at all when that's=

$\mathrm{T}:\left[{ }^{\circ} \mathrm{hm}^{\circ}\right]$

P: =completely inappropriate or when it's just not at all

$\mathrm{T}: \mathrm{hm}$

P: asked for from him, I mean there's people there

T: ${ }^{\circ} \mathrm{mhm}^{\circ}$

P: should you LAUGH about that or or it is ok;

T: $\mathrm{mhm}$

P: .h but it's (.) just that he always gets (-) too close for comfort

This is a segment from the first two minutes of the 15 th session. One can easily see that she reports an interactional episode with the colleague where he produces 
sexual allusions in a way that fulfill the criteria we just mentioned. He alludes to something and he does not; he is described to speak in an unmotivated way and to exonerate himself at the same time as nothing was really said. The patient, however, is upset, as she has to bear the burden of how to respond. She describes his behavior in citational details. The use of citation format (Bergmann 1987) is often found to be used when increased claims to authenticity are made.

We find this conversationally artful, but morally problematic use of ambiguity in gossip (Bergmann, 1987), in flirtation (Phillips, 1994) and in intrigues (Buchholz, 2003), too. The categorization of the colleague's behavior as allusion is cognitively transparent and conversationally uttered as accusing or, at least, complaining. What the patient does not openly talk about is what she expects the therapist to do.

\section{Methodological considerations}

Before we continue we want to insert a reflection on expectations in cooperation. In many types of cooperation (Noble 2000, Schweikard 2017, Tomasello 2013) mutual expectations must be expressed - with reference to context often minimalistically - and action types are to be described in order to promote the common project. Although psychotherapy can be considered as a cooperative project it is often observed (Safran et al., 2000) that cooperation breaks down when expectations are not made clear or cannot be inferred - from both sides. A musicologist (Huron 2006) finds it necessary to base musical listening on a psychological theory of expectation. Expectations, many of them unconscious (Huron 2006, p. 3), have 5 components:

a) imagination-guiding future-oriented behavior

b) tension- preparing arousal and guiding attention to anticipated events

c) prediction-makes learning possible by preparing for anticipated events

d) reaction-preparation for worst-case

e) appraisal-comparing imagined anticipation and the real outcome of events

Huron's theory is far-reaching and interesting for psychology and conversation analysis because he can include mixed emotions (as surprise, disappointment) and mixed emotional utterances (as sarcasm or irony). For instance, it is possible to make a clear negative prediction and when things indeed come out negatively, the appraisal response generates feelings of disappointment, but when the prediction is correct, at the same time proud is felt with an increase of self-worth. And, the components of Huron's expectation theory explain how cognitive and

emotional learning is possible.

We cannot discuss this theory in its full aspects here. To hide or omit to formulate expectations is an important feature of the allusive format. The patient while talking about the sexual allusions of her male colleague is engaged in an allusive conversation herself. The recipient is forced to conclude what the speaker's expectations might be. Thus, allusions increase a risk for the recipient not only to fail the speaker's expectations and, what is more, to bear the responsibility for this failure and to become accused for the failure. To play with these outcome-risks is enjoyed in flirt where the the distribution of risk is balanced. It is imbalanced in intrigue. In gossip a possible risk is attributed to the object of gossip talk - who is not present.

After inserting these considerations, we come back to the minimalistic responses of the therapist which can be considered as self-protective behavior provoked by the risk of falsely guessing the patient's expectations in her narration.

We summarize in a nutshell what the patient tells next. She speaks extensively about a little girl who did not hide her dislike of this male colleague and who tried to hide whenever he appeared. She concludes by saying that she has a kind of natural instinct against badness as animals have it, too. She adds that she feels like the little girl and that she has such an instinct, too. She describes him further:

P: He isn't REAL there's nothing authentic about him that's all (-) he's always just acting, that guy, he $()=$.

$\mathrm{T}:={ }^{\circ} \mathrm{hm}^{\circ}$ (2.2)

P him (.) when he smiles he isn't smiling <because it's not coming from heart>, but

P: because (.) he wants to get something with his smile (.) that (.) so that's (.) that's what's kind of happening in that moment inside me subconsciously (.) when that guy (-) is being friendly and saying something nice then it's not really meant seriously (.) honestly

T: ((loudly clears throat, several seconds)) (11.3)

The object of her dislike is described as smiling, but not from heart; as if artificially instrumentalizing smile for hidden purpose. His kindness is false and dishonest, honestly (speaking) the patient adds. Here the therapist's body reacts; he loudly tries to clear his throat and a pause of $11.3 \mathrm{sec}$ follows. Based on the theory of expectations and allusive formats such bodily reactions can become relevant data for CA.

In a data session some readers of the transcript understood the patient to be talking directly about the therapist. Clearly she isn't. Or is she? The question arises whether his body reaction and the long pause should be considered as part of his embodied participation or merely as accidental. What might he have reacted to?

We made the decision of going through the material again and found how much this patient was talking in the 
first session. For more than 19 minutes in the first session the therapist hardly produces anything more than goahead tokens and then there is the following segment with a first full utterance by the therapist in this first session:

P: (...) so (.) I gotta force myself every morning to

$\mathrm{T}:[\mathrm{mh}][\downarrow \mathrm{hm}]$

P: go to work at all hh and to do anything at all, at the moment (.) it's all just so (.) erm (.) terribly exhausting, 'cause I gotta force myself to do everything (.) nothing anymore is so

$\mathrm{T}$ : $\mathrm{it}=\mathrm{is}$ exhausting here for you as well (.) I notice that you're kind of having to cough and swallow again and again (1) you know, you're talking very lively but [that] doesn't correspond really

$\mathrm{P}:[\mathrm{hm}]$

T: to your inner (.) state (-)

P: Yeah

In his first utterance in the initial session the therapist addresses the patient's bodily reactions (cough, swallow, talking very lively) and concludes them as imbalanced with (what he terms as) the inner state of the patient. The therapist uses the phrase here for you as well. Analogies of this kind create a connection between the outside narration and the situation at hand; they are well known in psychodynamic orientation. However, he is a CBT-therapist. He concludes from her narration of outside events, treating the narration as allusion to the situation within the treatment room. Uttering I notice that ... his observer response (Heritage 2011), establishes a rule with two components: a) normatively: bodily reactions and inner state should be in a kind of healthy balance; b) conversationally: bodily reactions can be directly noticed.

Another cultural rule is introduced. In everyday conversation, such utterances are mostly tabooed, most people in the Western World are socialized to overlook bodily reactions of others in most cases. Ekman calls self-touching behavior during interaction manipulator actions or self-adaptors. Talking anecdotally about children's selftouching in public, he observes that in most cases we are told not to look when the other person cleans his ear, picks his nose, scratches his crotch. (Ekman 1977, p. 48). These observations were confirmed by an experimental study showing that bodily utterances, self-touchings, sniffings etc. are remembered far less than documented in videorecordings (Hall, Murphy, \& Schmid Mast, 2007). The frame of conversation to be established in psychotherapy, however, sometimes overcomes everyday rules and this is what most patients are implicitly taught, here right from the first session. Patients can reverse this rule - concluding from bodily reactions of their therapists to inner states. We conclude that the therapist implicitly could have understood that the patient is not only talking about her male colleague but that his body reacted to the intransparency of her expectations. He had to decide if she uses the nar- ration as an allusion to himself. We conclude this as the therapist reacts like people do when they hear a kind of double talk (as in flirtation, intrigues etc.): reaction time is extended because one must decide to what side of the talk one should respond to? And, even more if the listener (the therapist) has to cope with an affective task: Is it true that I am such an unloveable person? Am I a seducer? And: did the speaker really address me? The pause is motivated. Contextual embedding of silences should attract attention from other CA-researchers.

Clinical situations seem to be extremely complex. The patient's narration confronts the therapist with a lot of tasks to be solved. We know this withdrawal in silence from patients, e.g. when doctors try to inform them about a non-medical cause of their complaints and attempt a psychosomatic hypothesis. Often patients respond with a dismissal of the psychosomatic attribution, they change topic or undermine the meaning or - they fall in silence. They seem to understand the psychosomatic attribution as face threatening other positioning, as Burbaum et al. (2010) find in their study of 144 cases of this type. The therapist falls into silence after clearing his throat because he responds in a similar way as if he were face threatening other positioned.

\section{Temporary symptom formation}

In clinical situations it is not rare that topics, phrases, episodes or only single words are taken up again many sessions later. Package-by-package-analysis shows to what high degree of complexity participants sometimes organize their conversations. Here is another example where the two participants try to handle a complicated symptom, tinnitus.

The start of the second therapy session goes wrong: the telephone rings, the reflections of light from the patient's glasses irritate the therapist so that she wants to change seats. The patient declares that she knows about the strong reflections her glasses produce and adds that this is why she has chosen to sit near the window. This is a surprising remark. Near the window, where she sits, was just the place bothering the therapist! So the question arises: did the patient choose that place in order to avoid or to produce the disturbing reflection? Although the participants do not talk about this topic one gets a hunch that a complex but inconsistent interaction is beginning.

After diplomatic apologies for the trouble that has been caused both talk about how to treat tinnitus. The therapist brings in his authority and recommends relaxation techniques through self-hypnosis when tinnitus appears. This recommendation is ended by the therapist.

\section{Psychodynamic therapy D 26, $2^{\text {nd }}$ session: Tinnitus, passagère symptom formation in the session}

T: how clear do you have that for your daily life? (1.4)

P: WELL YEAH I (-) do GET IN:TO ONE of these situations now 
T: $\left[{ }^{\circ} \mathrm{mhm}^{\circ}\right]$

P: and then and then

(-)

P: I try to make myself (.) aware quickly (-) that I shouldn't get into this you know that I should somehow try to distract myself $=$

$\mathrm{T}:={ }^{\circ} \mathrm{mhm},{ }^{\circ}(-){ }^{\circ} \mathrm{mhm} ;{ }^{\circ}=$

$\mathrm{P}:=$ well I mea::n right now (-) it's just here ${ }^{\circ}$ by the way! ${ }^{\circ} \mathrm{CH}(\mathrm{HE}[(\mathrm{H}) \mathrm{E}(\mathrm{H}) \mathrm{E}]$

T: $[(\mathrm{H}) \mathrm{E}(\mathrm{E}) \mathrm{E}] \cdot \mathrm{hh}$

P: E:rm

T: ((clicking fingers)) You got it (.) differently on the two ears, right? (-)

P: yea:h (.) WELL NOW IT WAS JUST do:ing a kind of: (-) si::::; BUT ONLY REALLY SHORT! sometimes you got that you know ${ }^{\circ}$ that the ear ${ }^{\circ}$ kind of: (.)

T: stings!=

$\mathrm{P}$ : $=$ kind of closes

Here happens what Ferenczi (1927) termed a passagère (temporary) symptom formation during a session. Right the moment they are talking about it the tinnitus appears in the patient's ear! Although Luborsky (1996) illustrated carefully how the context matters when symptoms appear in a session we do not know of an example in the literature about psychotherapy where such a symptomatic upshot during the session has been presented in conversational details.

Again, we find a strong participation of the body that is conveyed by symbolic expressions embedded in an antagonistic cooperation how tinnitus is to be treated. Both cooperate as long as talk-in-interaction continues, but their talk serves the articulation of fundamental differences about this cooperation, its methods and aims. Conversation analysis cannot persist here in analyzing sequence organization, study repair activities or action organization, it has to step to the level of word selection (Madill, 2015) and categorization (Lepper, 2000) which was within the realm of Harvey Sacks' project.

So we can study how the antagonistic cooperation forms the context for temporary symptom formation here.

The therapist recommends either to fight the tinnitus or to evade it by relaxation. Metaphorically speaking, the tinnitus - as is often the case in medical discourse - is treated like other symptoms, as enemy. From what follows, concludably:fight or flight.

However, the patient interprets the tinnitus completely different. The tinnitus closes her ears against the therapist's recommendations. The tinnitus appears as an ally for her opposition against the therapist. This variant does not leave the fighting scenario, it introduces simply another possibility.

First, we have an antagonism of methods: fight or flight the tinnitus? Second, we have an antagonism of how the tinnitus is conceptualized: as enemy or as (furtive) ally?
The two participants, among other things, now debate how the tinnitus is to be understood.

T: it's more like a kind of sensitive- $(-)$ a kind of sensitivity ((construction noise from outside)) for something .hh (-) and you have now (-) let me say it like that (-) erm you've decided to pick out the tinnitus, right, $\mathrm{ch}(\mathrm{h})(-)$ and

P: yeah; e(h)ch(h)e (-)

T: you're certainly

P: $[(($ clears throat $))]$

T: [well] taken care of, aren't you (- $\left.{ }_{-}\right)$((clicking sound from a pen))

P: .h yeah e $(\mathrm{H})$ che $(\mathrm{H}) \mathrm{e}$

T: (H)e(H)e che(h)e (-)

P: mhmh; (-)

$\mathrm{T}$ : is it possible to say it like that? (-)

P: yes

Here the therapist addresses the patient as active agent in having made a decision for the tinnitus. The decision for this symptom appears in a special context: the therapist wanted to exonerate the patient, who has a psychotic brother, from her fear that she might suffer from a genetically inherited illness. In this context the therapist's remark achieved a hidden double meaning: where the brother decided for psychosis the patient decided for tinnitus. This is an antagonist utterance in itself: it can be heard as exoneration, but it gives the burden of decision, and hence: guilt, to the patient.

By viewing psychosis and tinnitus as functionally equivalent the therapist concludably concatenates several meanings: he constructs the patient's self as an active agent who made a decision for tinnitus; tinnitus, as compared to the brother's psychosis, appears as object of $a$ better choice. Again, the patient offers a completely different frame to make sense of her tinnitus:

P: well now the:re's some sounds (.) when I'm listening to music and then erm the blowing appears and I'll say alright (.) ((clicking fingers)) it's just like that

T: hmhm, (- $)$

P: a::nd now this HIGH-pitched sound after driving the car it's something I was expecting a little already that ${ }^{\circ}$ it might happen ${ }^{\circ}(-)$ something kind of (-) BUT still it's li:ke that maybe I'm suffering a bit more then ((clicking fingers)) 'cause (1.4) I know I just overdid it with the music, 'now it's just that ${ }^{\circ}$ I gotta step back on it a little (.) and when I'm (-) listening to music it's li:ke saying right I'm gonna sin now for a bit, ((both laughing out loud))

P: $\mathrm{BU}: \mathrm{T}=$

$\mathrm{T}:=$ EAT CANDIES [AND GROW FAT]

P: [OTHER THINGS] 
Framing tinnitus as punishment for the sin of listening to music, is repeated by the patient three times during the session. Both laugh about this. The therapist contributes a parallel to another sin (eating candies with the punishment of growing fat). We have a network of different concludable concatenations. In the patient's frame tinnitus is a) an ally that appears when ears are to be closed; b) a punishment for certain sins. In the therapist's frame tinnitus is something the patient once has decided for, an enemy to be fought against or to be evaded. From both frames follow completely divergent directives how to treat tinnitus: the patient takes a kind of bowing-the-headstance, calmly pre-calculating punishment after having committed her sins; the therapist takes a warrior-stance. Both frames can hardly be imagined to be more contradictory. But the agentive-decisional theory (by the therapist) and the sin-punishment theory fit in projecting guilt onto the patient's (wrong) decisions.

Package-by-package analysis can show how this antagonistic cooperation is continued over long time, the antagonism, it seems, could not be resolved. Fifteen sessions later, the agentive-decisional theory and the sin-punishment theory are confronted directly. However, the metaphor of a fight between the two conceptions is introduced.

\section{Psychodynamic therapy D 27, Tinnitus, continued}

T: .HH SO IT'S GONNA BE LI:KE that it'll stay a somewhat

P: $\mathrm{I}$ erm $=$

T: TOUGH FIGHT, won't it? (1.7)

P: you should get $[(\mathrm{H}) \mathrm{E}(\mathrm{H}) \mathrm{E}$ discouraged by that $]$

T: [CH(H)E (H)E(H)E(H)E (H)E(H)E (h)e(h)e] .hhhh=

P: $=$ ah because

T: I should [arrange myself more with that, shouldn't I?]

P: [I got the feeling if I don't] erm get on top of this small mountain (-)

T: you:: (-) won't get [on ${ }^{\circ}$ top of it ${ }^{\circ}$

P: [as a punishment I'll] get an even larger mountain where I have to make an even greater effort

This therapeutic relationship is extremely complex. There is the episode with the reflecting glasses followed by rearrangement of sitting positions. There is the proud announcement that the tinnitus, like a jamming transmitter, in actu shows up in a moment when the therapist wants the patient to listen - as if the patient enacts the metaphor of her tinnitus as an ally in her fight with the therapist, the tinnitus helps her to close her ears against the therapist's words. We have the antagonisms of methods, conceptualizations and aims. In this last segment the patient produces a Freudian slip consistent with this analysis; the patient wants the therapist to be discouraged as a fighter against tinnitus and again the idea that the tinnitus is a punishment follows from the patient's framing. Although the patient seems to rejoice over the therapist, their antagonistic interaction is metaphorically termed as tough fight and both produce some laughter. The grim touch of this interaction seems to vanish.

\section{Discussion}

This is an exploratory study, the transcripts document verbal and non-verbal data. Not a huge number of cases was presented, but a technique of conversational microanalysis with the aim to combine these micro-data with larger chunks of narration as they are usually heard in the therapeutic office.

In a first part a new perspective on common ground and on therapeutic complexity emerged which needs further study. To describe common ground as talk-in-interaction makes clear in our view that to achieve a dyadic state of consciousness is the most relevant emotional precondition for influential therapeutic talk and contact. This is a genuine CA-contribution to a debate about technique vs relationship in psychotherapy. Techniques should be evaluated after considering the levels of common ground resp. dyadic state of consciousness. Here CA unfolds a unique view on the micro-analytic details bringing not yet described therapeutic techniques to awareness. Sometimes admirable skills can be detected, sometimes psychotherapists can learn about unacknowledged process contributions (Georgaca, 2009). We agree with Madill (2015, p. 513): In fact, conversation analysis may be the method par excellence for raising to awareness tacit skills of both therapist and client in progressing the therapeutic project: fine-grained, moment-by-moment, making the ordinary appear extraordinary.

In the second part of this paper we abandoned the level of sequence organization and turned to package-by-package analysis. We studied shifting agency, how people in therapy make and hear allusions, use metaphors. We found that metaphors appear not simply on a verbal level (fight, punishment etc.) consistent with culturally coherent treatment rules, but that metaphors can be implicitly enacted (using and defending the tinnitus as ally). And, one step further, metaphors are more than illiterate, pictorial expressions; they are used as frames (for symptoms and therapeutic recommendations). Metaphoric conceptualizations can be enacted implicitly. Implicit framing activities were analyzed as context for temporary symptom formation.

Such implicit framings and their antagonisms contribute to highly complex situations in therapeutic conversation, not often described in the CA-literature on psychotherapy. Metaphorical frames seem to unfold a kind of hidden steering quality how things are to be heard, said - and cured. Concatenation of metaphorical meanings and frames unfold when one observes concatenations 
of episodes, words or symptoms. CA has the potential to integrate these complex dimensions of meaning organization in conversation; however, the future will have to work out more details of methodological rules. Here is a challenge for CA in psychotherapy process research. CA can pay methodological attention to the influence of something invisible and not-hearable, e.g., expectations, even when they are omitted; implicit metaphorical frames, when they are not formulated, but are presented as concludables. This is the meaning how we use the adjective implicit here. Concludables are made very fast by participants, their reconstruction takes a lot of time. They form the base for nextness, one of the CA-principles.

Training of psychotherapists could be enriched by studying implicit, but in its effects far reaching conclusions participants draw from each other's utterances.

As the prominent editor of the 6th volume of Bergin and Garfield's Handbook of Psychotherapy and Behavior Change, Michael Lambert, remarks: although there is a high investment of money and intellect and a huge public interest in psychotherapy and its effects in relation to competing approaches, research into the processes and effects of psychotherapy remains much less known and, to some degree a minor aspect of the endeavors falling under the rubric of psychotherapy with its emphasis on theory and practical application (Lambert, 2013, p.3).

\section{Conclusions}

CA has a huge potential to overcome the lack of knowledge and understanding therapeutic conversation. It is time to bring therapeutic framework and methodological concepts of analyzing conversation in therapy closer together. There are many things that happen in psychotherapy conversation that are not covered by prevailing theoretical concepts. How psychotheray is performed will always wait for full description and analysis. But to study these processes in details and frames (and in their effect for therapy outcome) will be a task for further research.

\section{References}

Alder, M.-L. (2016). Dream-telling - Differences in psychotherapy (June, 10th). ICCAP 2016. 8th Intern. Conference on Conversation Analysis and Psychotherapy, Helsinki.

Auer, P. (2014). The temporality of language in interaction: Projection and latency. Interaction and Linguistic Structures, $54,1-25$.

Baumeister, R.F. (1991). Self concept and Identity. In V.J. Derlega, B.A. Winstead, \& W.H. Jones (Eds.), Personality: Contemporary theory and researches (pp. 313-332). Chicago: Nelson.

Beebe, B. (2014). My journey in infant research and psychoanalysis. Microanalysis, a social microscope. Psychoanalytic Psychology, 31(1), 4-25. doi:10.1037/a0035575

Bergmann, J.R. (1987). Klatsch. Zur Sozialform der diskreten Indiskretion. Berlin/New York: de Gruyter; W. de Gruyter.
Blatt, S.J., Auerbach, J.S., \& Behrends, R.S. (2008). Changes in the representations of self and significant others in the treatment process. In E.L. Jurist, A. Slade, \& S. Bergner (Eds.), Mind to mind. Infant research, neuroscience and psychoanalysis (pp. 225-264). New York: Other Press.

Blumer, H. (1969). Symbolic interactionism. Berkeley: University of California Press.

Bollas, C. (1999). The mystery of things. London/New York: Routledge.

Bromberg, P.M. (2008). Mentalize this. Dissociation, Enactment, and Clinical Process. In E.L. Jurist, A. Slade, \& S. Bergner (Eds.), Mind to mind. Infant research, neuroscience and psychoanalysis (pp. 414-435). New York: Other Press.

Bruner, J.S. (1979). On knowing: Essays for the left hand (Expanded ed.). Cambridge, Mass.: Belknap Press of Harvard University Press.

Buchholz, M.B. (2003). Aufklärung über Realität und ihre Prinzipien: Intrige und Wettstreit der Kategorien. Psychotherapie \& Sozialwissenschaft, 5, 43-63.

Buchholz, M.B. (2016). Conversational errors and common ground activities in psychotherapy - Insights from conversation analysis. International Journal of Psychological Studies, 8(3), 134-153. doi:10.5539/ijps.v8n3p134

Buchholz, M.B., Bergmann, J.R., Alder, M.-L., Dittmann, M.M., Dreyer, F., \& Kächele, H. (2017). The Building of Empathy: Conceptual 'pillars' and Conversational Practices in Psychotherapy, In: Kondo, Makiko (Hrsg.). Empathy - An evidence-based interdisciplinary perspective. https://www. intechopen.com/books, Open Access, InTech.

Buchholz, M.B., \& Kächele, H. (2013). Conversation analysis A powerful tool for psychoanalytic practice and psychotherapy research. Language and Psychoanalysis, 2(2), 4-30.

Buchholz, M.B., \& Kächele, H. (2016). Introduction to the Special Issue: Conversation Analysis in Psychotherapy Process Research. Language and Psychoanalysis, 5(2), 4-10.

Burbaum, C., Stresing, A.-M., Fritzsche, K., Auer, P., Wirsching, M., \& Lucius-Hoene, G. (2010). Medically unexplained symptoms as a threat to patients' identity? A conversation analysis of patients' reactions to psychosomatic attributions. Patient Education and Counseling, 79, 207-217.

Castonguay, L.G., Boswell, J.F., Constantino, M.J., Goldfried, M.R., Wiser, S., Raue, P.J., \& Hayes, A.M. (1996). Predicting the effects of cognitive therapy for depression: A study of unique and common factors. Journal of Consulting and Clinical Psychology, 64, 497-504.

Corballis, M.C. (2011). The recursive mind: The origins of human language, thought, and civilization. Princeton: Princeton University Press.

Dahl, H. (1972). A quantitative study of psychoanalysis. In R.R. Holt \& E. Peterfreund (Eds.), Psychoanalysis and contemporary science (pp. 237-257). New York: Macmillan Company.

Dimitrijevic, A. (2014). Fairbairn's influence on Stephen Mitchell's theoretical and clinical work. In G.S. Clarke \& D.E. Scharff (Eds.), Lines of development : evolution of theory and practice over decades. Fairbairn and the object relations tradition (pp. 355-364). London: Karnac Books.

Ekman, P. (1977). Biological and cultural contributions to body and facial movement. In J. Blacking (Ed.), The anthropology of the body (pp. 39-84). London: Academic Press.

Ferenczi, S. (1927/1984). Über passagère Symptombildungen während der Analyse (Passagère Konversion, Substitution, Illusion, Halluzination, 'Charakterregression' und 'Ausdrucksverschiebung'. In S. Ferenczi (Ed.), Bausteine zur 
Psychoanalyse, Band II: Praxis (pp. 9-37). Frankfurt/ Berlin/Wien: Ullstein.

Gafaranga, J., \& Britten, N. (2005). Talking an institution into being: the opening sequence in general practice consultations. In K. Richards \& P. Seedhouse (Eds.), Applying conversation analysis (pp. 75-90). Houndmills, Basingstoke, Hampshire, New York: Palgrave Macmillan.

Georgaca, E., \& Avdi, E. (2009). Evaluating the talking cure: The contribution of narrative, discourse, and conversation analysis to psychotherapy assessment. Qualitative Research in Psychology, 6(3), 233-247. https://doi.org/10.1080/ 14780880802146896

Gill, M.M., Simon, J., Fink, G., Endicott, N.A., \& Paul, I.H. (1968). Studies in audio-recorded psychoanalysis. I. General considerations. Journal of the American Psychoanalytic Association, 16, 230-244.

Goncalves, M.M., Ribeiro, A.P., Matos, M., Mendes, I., \& Santos, A. (2009). Innovative moments coding system: A methodological procedure for tracking changes in psychotherapy. Yearbook of Idiographic Science, 2, 107-130.

Greenberg, J.R., \& Mitchell, S.A. (1983). Object relations in psychoanalytic theory. Cambridge: Harvard University Press.

Hall, J.A., Murphy, N.A., \& Schmid Mast, M. (2007). Nonverbal self-accuracy in interpersonal interaction. Personality and Social Psychology Bulletin, 33, 1675-1685. doi:10.1177/ 0146167207307492

Ham, J., \& Tronick, E. (2009). Relational psychophysiology: Lessons from mother-infant physiology research on dyadically expanded states of consciousness. Psychotherapy Research, 19, 619-632.

Henretty, J.R., Levitt, H.M., \& Mathews, S.S. (2008). Clients' experiences of moments of sadness in psychotherapy: a grounded theory analysis. Psychotherapy Research, 18, 243-256.

Heritage, J. (1984). A change-of-state token and aspects of its sequential placement. In J. M. Atkinson \& J. Heritage (Eds.), Structures of social action (pp. 299-346). New York: Cambridge University Press.

Heritage, J. (2011). Territories of knowledge, territories of experience: empathic moments in interaction. In T. Stivers, L. Mondada, \& J. Steensig (Eds.), The morality of knowledge in conversation (pp. 159-183). Cambridge/New York: Cambridge University Press.

Heritage, J. (2012). The epistemic engine: Sequence organization and territories of knowledge. Research on Language \& Social Interaction, 45(1), 30-52.

Hill, C.E. (2011). Qualitative research in counseling and psychotherapy. Psychotherapy Research, 21(6), 736-738.

Huber, D., Henrich, G., Gastner, J., \& Klug, G. (2011). Must all have prizes? The Munich Psychotherapy Study. In R.A. Levy, S.J. Ablon, \& H. Kächele (Eds.), Psychodynamic psychotherapy research. Evidence-based practice and practice-based evidence (pp. 51-71). Totowa, NJ: Humana Press Inc.

Huron, D. (2006). Sweet anticipation - Music and the psychology of expectation. Cambridge: MIT Press.

Hutchins, E., \& Nomura, S. (2011). Collaborative construction of multimodal utterances. In J. Streeck, C. Goodwin, \& C.D. LeBaron (Eds.), Learning in doing: social, cognitive and computational perspectives. Embodied interaction. Language and body in the material world (pp. 29-43). New York: Cambridge University Press.

Ilardi, S.S., \& Craighead, W.E. (1994). The role of nonspecific factors in cognitive-behavior therapy for depression. Clinical Psychology: Science and Practice, 1, 138-156.

Jacobson, N.S., Martell, C.R., \& Dimidjan, S. (2001). Behavioral activation treatment for depression: Returning to contextual roots. Clinical Psychology: Science and Practice, 8 , 255-270.

Jefferson, G., Drew, P., Heritage, J., Lerner, G.H., \& Pomerantz, A. (2015). Talking about troubles in conversation. Foundations of human interaction. Oxford, New York: Oxford University Press.

Kächele, H., \& Thomä, H. (1995). Psychoanalytic process research: Methods and archievements. In T. Shapiro \& R.N. Emde (Eds.), Research in psychoanalysis: Process, development, outcome (pp. 109-130). Madison: International Universities Press.

Kondratyuk, N., \& Peräkylä, A. (2011). Therapeutic work with the present moment: A comparative conversation analysis of existential and cognitive therapies. Psychotherapy Research, 21, 316-330.

Korner, A. (2015). Analogical Fit: dynamic relatedness in the psychotherapeutic setting with reference to language, autonomic response, and change in self-state (Dissertation). Macquarie University, Sydney.

Ladany, N., Friedlander, M.L., \& Nelson, M.L. (2005). Critical events in psychotherapy supervision. An interpersonal approach. Washington: American Psychological Association.

Lambert, M.J. (2013). Introduction and historical overview. In M. J. Lambert (Ed.), Bergin and Garfield's handbook of psychotherapy and behavioural change, 6th Edition. Hoboken, NJ: John Wiley \& Sons.

Leary, K. (2008). Critical moments as relational moments. In E.L. Jurist, A. Slade, \& S. Bergner (Eds.), Mind to mind. Infant research, neuroscience and psychoanalysis (pp. 335353). New York: Other Press.

Leiman, M. (2012). Dialogical sequence analysis in studying psychotherapeutic discourse. International Journal for Dialogical Science, 6(1), 123-147.

Lepper, G. (2000). Categories in text and talk. A practical introduction to categorization analysis. London/Thousand Oaks/New Delhi: Sage Publications.

Levinson, S.C. (2006). On the human "Interaction Engine". In S.C. Levinson \& N.J. Enfield (Eds.), Roots of human sociality. Culture, cognition and interaction (pp. 39-69). Oxford: Berg Publishers.

Levinson, S.C., \& Enfield, N.J. (2006). Roots of human sociality. Culture, cognition and interaction. Oxford: Berg Publishers.

Lippe, A.L., von der, Monsen, J.T., Ronnestad, M.H., \& Eilertsein, E. (2008). Treatment failure in psychotherapy: The pull of hostility. Psychotherapy Research, 18(4), 420-432.

Liszkowski, U. (2006). Infant pointing at 12 month: Communicative goals, motives, and social-cognitive abilities. In S.C. Levinson \& N.J. Enfield (Eds.), Roots of human sociality. Culture, cognition and interaction (pp. 153-178). Oxford: Berg Publishers.

Luborsky, L. (1996). The symptom-context method. Symptoms as opportunities in psychotherapy. Washington, DC: American Psychological Assocation.

Madill, A. (2015). Conversation analysis and psychotherapy process research. In O.C. Gelo, A. Pritz, \& B. Rieken (Eds.), Psychotherapy research (pp. 501-516). Vienna: Springer Vienna.

McLeod, J. (2011). Qualitative research in counselling and psychotherapy (2nd ed.). London: Sage. 
Mergenthaler, E. (2008). Resonating minds: A school-independent theoretical conception and its empirical application to psychotherapeutic processes. Psychotherapy Research, 18, 109-127.

Meyer, A.E. (1962). Der psychoanalytische Dialog: seine methodischen Determinanten und seine grundsätzlichen Möglichkeiten zur Verifizierung und Validisierung psychoanalytischer Thesen. Die Medizinische Welt, 47, 2439-2445.

Mitchell, S.A. (1988). Relational concepts in psychoanalysis. An integration. Cambridge: Harvard University Press.

Muntigl, P., \& Bänninger-Huber, E. (2016). Affiliation in der psychotherapeutischen Interaktion: Die Untersuchung der therapeutischen Beziehung aus der Perspektive der Konversationsanalyse. In E. Bänninger-Huber \& S. Monsberger (Eds.), Prozesse der Emotionsregulierung in psychoanalytischen Langzeittherapien (pp. 135-150). Innsbruck: Innsbruck University Press.

Muntigl, P., \& Horvath, A.O. (2014). "I can see some sadness in your eyes": When experiential therapists notice a client's affectual display. Research on Language and Social Interaction, 47(2), 89-108.

Noble, J. (2000). Cooperation, competition and the evolution of prelinguistic communication. In C. Knight, M. StuddertKennedy, \& J.R. Hurford (Eds.), The evolutionary emergence of language. Social function and the origins of linguistic form (pp. 40-61). Cambridge, New York: Cambridge University Press.

Peräkylä, A. (2004). Two traditions of interaction research. British Journal of Social Psychology, 43(1), 1-20.

Peräkylä, A. (2012). Epilogue: What does the study of interaction offer to emotion research? In A. Peräkylä \& M.-L. Sorjonen (Eds.), Emotion in interaction (pp. 274-289). New York: Oxford University Press.

Peräkylä, A., Antaki, C., Vehviläinen, S., \& Leudar, I. (2008). Analysing psychotherapy in practice. In A. Peräkylä, C. Antaki, S. Vehviläinen, \& I. Leudar (Eds.), Conversation analysis and psychotherapy (pp. 5-26). Cambridge/New York: Cambridge University Press.

Phillips, A. (1994). On flirtation. London/Boston: Faber \& Faber.

Piazza-Bonin, E., Neimeyer, R.A., Alves, D., \& Smigelsky, M. (2016). Innovative moments in humanistic therapy II. Analysis of change processes across the course of three cases of grief therapy. Journal of Constructivist Psychology, 1-20. doi:10.1080/10720537.2015.1118713

Potter, J., \& Edwards, D. (2013). Conversation analysis and psychology. In J. Sidnell \& T. Stivers (Eds.), The handbook of conversation analysis (pp. 701-726). Chichester, West Sussex, UK: Wiley-Blackwell.

Powers, N., \& Trevarthen, C. (2010). Voices of shared emotion and meaning: Young infants and their mothers in Scotland and Japan. In S. Malloch \& C. Trevarthen (Eds.), Communicative musicality. Exploring the basis of human companionship (pp. 209-240). Oxford: Oxford University Press.

Russell, B. (1918). Knowledge by acquaintance and knowledge by description (first published 1910/11 in the "Proceedings of the Aristotelian Society"). In B. Russell (Ed.), Mysticism and logic, and other essays (pp. 209-232). New York: Longmans, Green and Co.

Sacks, H., \& Jefferson, G. (1992/1995). Lectures on conversation. Edited by Gail Jefferson, with an introduction by Emanuel A. Schegloff. Oxford: Basil Blackwell.

Sacks, H., Schegloff, E.A., \& Jefferson, G. (1974). A simplest systematics for the organization of turn-taking for conversation. Language, 50(4), 696-735.

Safran, J.D., Muran, J.C. (2000). Negotiating the therapeutic alliance - A relational treatment guide. New York: The Guilford Press.

Salvatore, S., Gennaro, A., \& Valsiner, J. (2012). Making sense of infinite uniqueness: The emerging system of idiographic science. YIS: Yearbook of idiographic science. Charlotte, NC: Information Age Pub.

Schegloff, E.A. (1996). Confirming allusions: Toward an empirical account of action. American Journal of Sociology, 102(1), 161-216.

Schlesinger, H.J. (1995). The process of interpretation and the moment of change. Journal of the American Psychoanalytic Assocociation, 43, 663-688.

Schweikard, D.P. (2017). Cooperation and Social Obligations. In N. J. Enfield \& P. Kockelman (Eds.), Distributed Agency (pp. 233-242). Oxford, New York: Oxford University Press.

Sidnell, J., \& Stivers, T. (2013). The handbook of conversation analysis. Chichester, West Sussex, UK: Wiley-Blackwell.

Stern, D.N. (2004). The present moment in psychotherapy and everyday life. New York/London: W.W. Norton \& Company.

Stiles, W.B. (1995). Stories, tacit knowledge, and psychotherapy research. Psychotherapy Research, 5, 125-127.

Stivers, T., Enfield, N.J., Brown, P., Englert, C., Hayashi, M., Heinemann, T., ..., \& Levinson, S.C. (2009). Universals and cultural variation in turn-taking in conversation. PNAS, 106(26), 10587-10592. doi:10.1073/pnas.0903616106

Thomä, H. (1968). Über einige Probleme und Ergebnisse der psychoanalytischen Prozessforschung (Some problems and results of psychoanalytic process research). Annual meeting of the German Psychoanalytic Association, Ulm.

Thomä, H., \& Kächele, H. (1994a). Psychoanalytic practice - Principles, vol. 1 (1st softcover ed.). The Master work series. Northvale, N.J.: Jason Aronson.

Thomä, H., \& Kächele, H. (1994b). Psychoanalytic practice Clinical Studies, vol. 2 (1st softcover ed.). The Master work series. Northvale, N.J.: Jason Aronson.

Tomasello, M. (2001). The item-based nature of children's early syntactic development. In M. Tomasello \& E. Bates (Eds.), Language development. The essential readings. Oxford: Blackwell Publishing.

Tomasello, M. (2003). The key is social cognition. In D. Gentner \& S. Goldin-Meadow (Eds.), Language in mind. Advances in the Study of Language and Thought (pp. 47-58). Cambridge, London: MIT-Press.

Tomasello, M., Carpenter, M., \& Liszkowski, U. (2007). A new look at infant pointing. Child Development 78, 705-722.

Tomasello, M., \& Rakoczy, H. (2009). Was macht menschliche Entwicklung einzigartig? Von individueller über geteilte $\mathrm{zu}$ kollektiver Intentionalität. In H.B. Schmid \& D.P. Schweikard (Eds.), Suhrkamp-Taschenbuch Wissenschaft: Vol. 1898. Kollektive Intentionalität. Eine Debatte über die Grundlagen des Sozialen (1st ed., pp. 697-738). Frankfurt am Main: Suhrkamp.

Tomasello, M., \& Vaish, A. (2013). Origins of human cooperation and morality. Annual Review of Psychology, 64(1), 231-255. https://doi.org/10.1146/annurev-psych-113011-143812

Trevarthen, C. (2011). What is it like to be a person who knows nothing? Defining the active intersubjective mind of a newborn human being. Infant and Child Development, 20(1), 119-135. doi:10.1002/icd.689

Tronick, E. (2007). The neurobehavioral and social-emotional 
development of infants and children. New York/London: W.W. Norton.

Vehviläinen, S., Peräkylä, A., Antaki, C., \& Leudar, I. (2008). A review of conversational practices in psychotherapy. In A. Peräkylä, C. Antaki, S. Vehviläinen, \& I. Leudar (Eds.), Conversation analysis and psychotherapy (pp. 188-198). Cambridge/New York: Cambridge University Press.

Wampold, B.E. (2001). The great psychotherapy debate - Models, methods and findings. Mahwah, $\mathrm{NJ} /$ London: Lawrence Earlbaum.

Wampold, B.E., \& Imel, Z.E. (2015). The great psychotherapy debate. The evidence for what makes psychotherapy work (2. ed.). New York: Routledge.

Willems, R.M. (Ed.). (2015). Cognitive neuroscience of natural language use. Cambridge, United Kingdom, New York: Cambridge University Press.

Williams, E.N., \& Morrow, S.L. (2009). Achieving trustworthiness in qualitative research: A pan-paradigmatic perspective. Psychotherapy Research, 19, 576-582.

Woolfolk, R.L. (2015). The value of psychotherapy: The talking cure in an age of clinical science. New York: The Guilford Press. 